\title{
Factors affecting reproductive traits in male snow leopards (Uncia uncia)
}

\author{
Jason R Herrick ${ }^{1,2}$, Cayla J Iske ${ }^{3}$, Rachel M Santymire ${ }^{4}$, Colleen Lynch ${ }^{5}$, Mattina Alonge ${ }^{4}$, Rebecca L Krisher ${ }^{2}$ and \\ Cheryl L Morris ${ }^{1,3}$
}

1Omaha's Henry Doorly Zoo and Aquarium, Omaha, Nebrask, USA ${ }^{2}$ Colorado Center for Reproductive Medicine, Lone Tree, Colorado, USA

3Department of Animal Science, lowa State University, Ames, lowa, USA

${ }^{4}$ Davee Center for Epidemiology and Endocrinology, Lincoln Park Zoo, Chicago, Illinois, USA

${ }^{5}$ Riverbanks Zoo and Garden, Columbia, South Carolina, USA

Correspondence should be addressed to J R Herrick; Email: jason.herrick@omahazoo.com

\begin{abstract}
The population of snow leopards (Uncia uncia) maintained in US zoos is no longer sustainable due to poor reproductive success. Our objective was to assess reproductive traits in male snow leopards and identify factors (markers of oxidative stress in seminal fluid, surveys of husbandry practices, gonadal and adrenocortical activity, dietary intake of various nutrients, and genetics) that may affect ejaculate traits and subsequent fertility. Ejaculates $(2.9 \pm 0.2 \mathrm{~mL})$ from 32 male snow leopards $\left(9.8 \pm 0.7\right.$ years; $38.6 \pm 0.8 \mathrm{~kg}$ ) housed at 27 institutions contained $119.2+26.0 \times 10^{6}$ spermatozoa, of which $75.1 \pm 2.3 \%$ were motile and $28.6 \pm 2.6 \%$ exhibited normal morphology. Overall, $34 \%$ of males produced $<5$ million spermatozoa and $27 \%$ of males produced spermatozoa with $<20 \%$ normal morphology. Activity of superoxide dismutase (SOD) in the seminal fluid was negatively correlated $\left(P<0.05, r^{2}=0.90\right)$ with normal sperm morphology. Husbandry practices, mean concentrations of fecal androgen metabolites (fAM), and baseline concentrations of fecal glucocorticoid metabolites (fGM), inbreeding coefficients, and generations each male was removed from the founders in their lineages were not correlated $(P>0.05)$ with the total number of spermatozoa or the proportion of spermatozoa with normal morphology. Total sperm count was positively correlated $\left(P<0.05, R^{2}=0.86\right)$ with the weekly intake of polyunsaturated fatty acids (PUFA) and the proportion of spermatozoa with normal morphology tended $\left(P<0.10, R^{2}=0.31\right)$ to be positively correlated with copper intake. Altering the nutrient composition of snow leopard diets could provide managers with a possible method of improving reproductive traits in this endangered species.
\end{abstract}

\section{Lay summary}

The population of snow leopards (Uncia uncia) maintained in US zoos has been declining since 1993 due to poor breeding success. Our objective was to assess the reproductive traits of male snow leopards and identify factors (e.g. hormones, diet, genetics) that may be affecting the quality of semen produced and therefore subsequent fertility. Within a cohort of 32 male snow leopards maintained at 27 US zoos, we found that 34\% produced less than 5 million sperm and $27 \%$ of males produced sperm where less than $20 \%$ looked normal. The quantity and quality of the recovered sperm was not correlated with husbandry practices, concentrations of hormones (androgens and glucocorticoids) in feces, or genetics. However, the number of sperm was positively correlated with polyunsaturated fatty acids in the diet. Altering the nutrient composition of snow leopard diets could provide managers with a possible method of improving reproductive traits in this endangered species.

Key Words $\quad$ snow leopard $\quad$ spermatozoa $\quad$ nutrition $\quad$ endocrinology

(c) 2020 The authors https://doi.org/10.1530/RAF-20-0013
Published by Bioscientifica Ltd

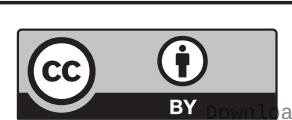

This work is licensed under a Creative Commons Attribution 4.0 International License. 


\section{Introduction}

The snow leopard (Uncia uncia) was listed as an endangered species by the International Union for Conservation of Nature and Natural Resources in 1986 (McCarthy et al. 2017). Although recently upgraded to vulnerable, wild populations continue to decline with less than 3,400 mature individuals thought to exist (McCarthy et al. 2017). A number of in situ conservation efforts have been initiated to prevent this species from becoming extinct, ranging from studies of the species' natural history to educating and supporting local communities (Jackson et al. 2010). The Association of Zoos and Aquariums' (AZA) Species Survival Plan® (SSP) also participates in conservation efforts for this species by managing $e x$ situ population of snow leopards that could be used to supplement or re-establish wild populations in the future. In addition, zoo populations of snow leopards are a valuable resource to study their basic biology and educate zoo visitors who will likely never have the opportunity to view a snow leopard in the wild.

The goal of the Snow Leopard SSP is to maintain a population of 150 individuals with at least $90 \%$ genetic diversity for 100 years (Soulé et al. 1986). Snow leopards have historically reproduced well in zoos, with steady population growth between the 1970s and the early 1990s (Tetzloff et al. 2019). However, the population has been declining since 1993 and is no longer considered sustainable. If current population trends continue, genetic diversity will fall below $90 \%$ in only 52 years. One of the primary factors contributing to these dire population projections is poor reproductive success. Since 2008, 40-49 pairs have been recommended to breed each year, but only 6-14 pairs per year have produced litters, resulting in average breeding success of only $19.3 \%$ per year. It is imperative that reproductive success improves in order for the zoo population to remain viable and contribute to the conservation of this species.

Despite the popularity of snow leopards in zoos, surprisingly little is known about their reproductive biology. There have only been three studies concerning the reproductive biology of male snow leopards (Johnston et al. 1994, Roth et al. 1994, 1996). In these studies, spermatozoa were recovered from all males ( $>31$ million per ejaculate) and the proportion of spermatozoa with normal morphology was high ( 60\%). However, all three of these studies were conducted prior to 1997, when reproductive success was high and the population was growing. There have been no published reports on the reproductive biology of male snow leopards in over 20 years.
The current study was designed to characterize ejaculates from male snow leopards in the current zoo population and determine if reproductive traits were correlated to husbandry practices, androgen concentrations, adrenocortical activity, nutrition, or genetics. Our specific objectives were to: (1) collect and analyze ejaculate traits in snow leopards; (2) assess husbandry practices at each institution; (3) validate the use of fecal glucocorticoid metabolites (fGM) to evaluate stress physiology using an adrenocorticotropin hormone (ACTH) challenge; (4) monitor fecal androgen metabolite (fAM) concentrations throughout the breeding season; (5) determine concentrations of nutrients, minerals, and vitamins in snow leopard diets; and (6) identify correlations between reproductive parameters, husbandry practices, endocrine traits, nutrition, and genetics.

\section{Materials and methods}

\section{Animals}

Male snow leopards in this study were included in the Snow Leopard SSP and maintained in USDA and/or AZAaccredited facilities. All procedures were reviewed and approved by the Animal Care and Use Committees of each institution.

\section{Reproductive exams and semen collection}

Between March 2009 and March 2019, 32 male snow leopards housed at 27 zoological institutions underwent reproductive exams and semen collections. According to studbook records, males between 2 and 19 years of age have sired offspring (Tetzloff et al. 2019). All males in the study fell within this age range. All males were immobilized using a combination of ketamine $(5.3 \pm 2.0 \mathrm{mg} / \mathrm{kg}$, range: $2.0-12.4$ ) and medetomidine or dexmedetomidine $(0.06 \pm 0.01 \mathrm{mg} / \mathrm{kg}$, range: $0.01-0.39)$. This combination was further supplemented with midazolam $(0.12 \pm 0.02$ $\mathrm{mg} / \mathrm{kg} ; n=16$ collections) or butorphanol $(0.33 \pm 0.08$ $\mathrm{mg} / \mathrm{kg} ; n=6$ collections) at the discretion of the attending veterinarian at each institution. In some cases, isoflurane ( $n=17$ collections) or propofol ( $n=8$ collections) were used to increase the depth and/or duration of anesthesia. All immobilizations occurred during the breeding season (January to June) (Johnston et al. 1994, Roth et al. 1997).

Prior to semen collections, the prepuce and glans penis were visually inspected and the length and width of each testicle were measured with calipers to the nearest

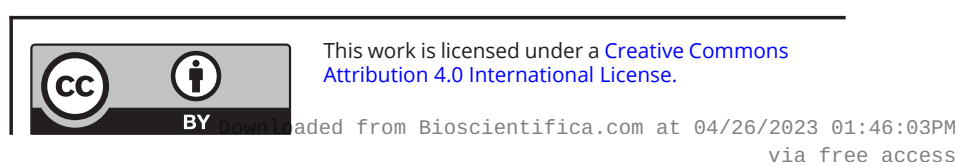


millimeter in order to calculate testicular volume (Howard 1993). Semen was collected via electroejaculation, using a protocol proven to be safe and effective for felids, including snow leopards (Johnston et al. 1994, Roth et al. 1996). Briefly, a lubricated probe $(2.5 \mathrm{~cm}$ diameter) with three longitudinal electrodes was inserted into the rectum and used to apply a series of controlled stimuli (three sets of 30 stimulations) with increasing voltage (2-6 V per stimuli) to the accessory glands through the ventral wall of the rectum. At the conclusion of each series, the volume of recovered sample was determined and small aliquots $(\sim 5$ $\mu \mathrm{L}$ ) were used to evaluate $\mathrm{pH}$ ( $\mathrm{pH}$ Indicator Strip; Millipore Sigma), the proportion of motile sperm $(0-100 \%)$, and sperm morphology (fixed in $0.4 \%$ glutaraldehyde) (Howard 1993, Herrick et al. 2010a). The remaining sample was diluted 1:1 with HEPES-buffered Feline Optimized Culture Medium (FOCMH) (Herrick et al. 2010a, Herrick 2019) and maintained at room temperature. At the conclusion of the procedure, the samples recovered from each series were combined to determine the overall concentration of spermatozoa $\left(\mathrm{x} 10^{6} / \mathrm{mL}\right)$ using a hemocytometer and the total number of recovered spermatozoa $\left(\mathrm{x} 10^{6}\right)$ was calculated. The combined sample was centrifuged $(300 \boldsymbol{g}$ for $10 \mathrm{~min}$ ) and the supernatant was centrifuged again at $1100 \mathrm{~g}$ for $10 \mathrm{~min}$. The final supernatant was aspirated and stored at $-80^{\circ} \mathrm{C}$ for seminal fluid analysis and spermatozoa were cryopreserved (Crosier et al. 2006, Herrick et al. 2010b). The morphology of 200 spermatozoa per ejaculate were visually assessed at $1000 \mathrm{x}$ to determine the proportion of spermatozoa with normal morphology, as well as the proportions of spermatozoa with an abnormal head, midpiece, or tail according to previously published standards for feline spermatozoa that have been used to characterize individual males, or species, as normospermic ( $>60 \%$ spermatozoa with normal morphology) or teratospermic $(<40 \%$ spermatozoa with normal morphology) (Howard et al. 1990, Howard 1993, Pukazhenthi et al. 2006a).

\section{Analysis of seminal fluid for oxidative stress markers}

Samples of diluted (1:1 with FOCMH) seminal fluid ( $n=9$ males) were analyzed for concentrations of thiobarbituric acid reactive substances (TBARS), protein carbonyls (PC), DNA/RNA damage, superoxide dismutase (SOD), and glutathione peroxidase (GPx) using commercially available assay kits purchased from Cayman Chemical Company according to the recommendations of the manufacturer. Ferric reducing antioxidant power (FRAP) was also assessed as an indicator of total antioxidant capacity based on the reduction of ferric iron $\left(\mathrm{Fe}^{+3}\right)$ to ferrous iron $\left(\mathrm{Fe}^{+2}\right)$ by the colorimetric reaction of ferroustripyridyltriazine complex (Benzie \& Strain 1996).

\section{Survey of husbandry practices}

While visiting each zoo for the reproductive exams on 14 males, the cat's exhibit and holding areas were observed and relevant animal care staff were interviewed to determine light exposure, relative proximity to other large carnivores, feeding practices, enrichment practices, and the number of care staff that interact with that individual.

\section{Validation of fecal glucocorticoid metabolite analysis using ACTH challenge}

Fecal samples were collected daily 4 days before and after an injection of ACTH (Sigma A0298, Adrenocorticotropic Hormone, fragment 1-24 human and rat; 400 IU total) (Wielebnowski et al. 2002a, Young et al. 2004) from one male located at Omaha's Henry Doorly Zoo and Aquarium (Omaha, NE). The administration of ACTH is intended to induce the secretion of cortisol from the adrenal glands, which will then be excreted in the feces within $96 \mathrm{~h}$, as observed in cheetahs (Terio et al. 1999).

\section{Analysis of fecal concentrations of androgen and glucocorticoid metabolites}

Fecal samples were collected three times per week during routine, daily maintenance of the animal's exhibit and holding areas throughout the same breeding season as the semen collections ( $n=14$ males). Samples were stored at $-20^{\circ} \mathrm{C}$ and shipped to the Lincoln Park Zoo Endocrinology Laboratory for analysis. For hormone extraction, $0.5 \mathrm{~g}$ of wet feces and $5 \mathrm{~mL}$ of $90 \%$ ethanol were mixed overnight, centrifuged (500 $\boldsymbol{g}$ for $20 \mathrm{~min}$ ), and the supernatant poured into clean tubes (Reichert-Stewart et al. 2014).

We determined the fGM concentrations using a cortisol double antibody enzyme immunoassay (EIA) modified from Schell et al. (2017). First, 96 wells plates were coated with a goat anti-rabbit (GAR) antibody (1:1000, Arbor Assay, Ann Arbor, MI) and incubated at room temperature for 1 day. Contents were poured out, plates were blotted dry and a blocking buffer (Arbor Assay) was added. Blocked plates were incubated at room temperature for 1 day. The blocking buffer was poured off, plates were blotted dry and stored at $5^{\circ} \mathrm{C}$ until used. Fecal extracts were diluted from 1:20 to 1:80. On the day of the EIA analysis, polyclonal cortisol antiserum (R4866)

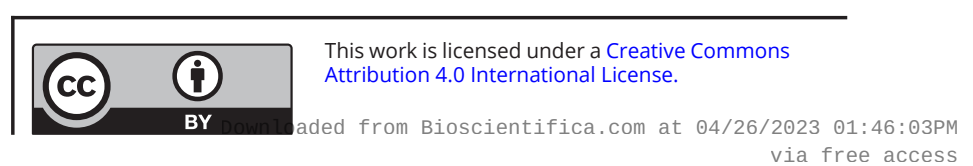


and horseradish peroxidase (HRP) ligands (provided by C. Munro; University of California, Davis, California) were used at dilutions of 1:375,000 and 1:200,000, respectively. The cross-reactivities for the cortisol antiserum were cortisol, 100\%, prednisolone, 9.9\%; prednisone, 6.3\%; cortisone, $5 \%$; corticosterone, $0.7 \%$; deoxycorticosterone, 0.3\%; 21-deoxycortisone, $0.5 \%$; 11-deoxycortisol, $0.2 \%$; progesterone, $0.2 \% ; 17 \alpha$-hydroxyprogesterone, $0.2 \%$; pregnenolone, $17 \alpha$-hydroxypregnenolone, anderostenedione, testosterone, androsterone, dehydroepiandrosterone, dehydroisoandrosterone3-sulfate, aldosterone, estradiol-17 $\beta$, estrone, estriol, spironolactone and cholesterol, 0.1\% (Young et al. 2004, Loeding et al. 2011). The fGMs were biochemically validated by determining: (1) parallelism between binding inhibition curves of dilutions of fecal extracts and the cortisol standards $(r=0.99)$; and (2) significant recovery of exogenous cortisol (3.9-1000 pg/well) added to fecal extracts $\left(\mathrm{y}=0.960 \mathrm{x}+3.402 ; R^{2}=0.998, P<0.001\right)$. The intra- and inter-assay CV were $<10$ and $<15 \%(n=35$ assays), respectively.

For fAM, a single antibody EIA system was used with testosterone horseradish peroxidase (HRP) ligands and polyclonal antiserum (R156/7; University of California, Davis, CA) at $1: 30,000$ and $1: 10,000$, respectively. Antiserum cross-reactivities for the testosterone antiserum were: testosterone, 100\%; 5a-dihydro-testosterone, 57.37\%; androstenedione, 0.27\%; androsteron and DHEA, $0.4 \%$; and cholesterol, $0.03 \%$. Cross-reactivity was $0.02 \%$ for the following: $\beta$-estradiol, progesterone, pregnenolone, hydrocortisone, cholic acid, chenodeoxycholic acid, cholic acid methyl ester, dehydrocholic acid, deoxycholic acid, lithocholic acid, glycholic acid, taurodeoxycholic acid, taurocholic acid, taurochendeoxycholic acid, and glycochenodeoxycholic acid (Santymire \& Armstrong 2010). The fAMs were biochemically validated for snow leopards by determining: (1) parallelism between binding inhibition curves of dilutions of fecal extracts and the testosterone standards $(r=0.993)$; and (2) significant recovery of exogenous testosterone (2.3-600 pg/well) added to fecal extracts $\left(\mathrm{y}=1.029 \mathrm{x}-6.258, R^{2}=0.994\right.$, $P<0.001)$. The intra- and inter-assay CV were $<10$ and $<15 \%$ ( $n=45$ assays), respectively. Baseline concentrations for cortisol were determined by an iterative process in which values that exceed the mean plus 2 s.D. were excluded. The average was re-calculated and the elimination process repeated until no values exceed the mean plus 2 s.D. Baseline values were determined after all high values have been excluded (Brown et al. 1996).

https://raf.bioscientifica.com

https://doi.org/10.1530/RAF-20-0013

\section{Nutritional analysis of diet}

A sample of the cat's diet ( $n=14$ males) was collected on the same day as the electroejaculation and stored at $-20^{\circ} \mathrm{C}$ until analysis. Diets were consistent for at least 2 months prior to sample collection. Approximately $200 \mathrm{~g}$ of each diet sample was subsampled, dried at $55^{\circ} \mathrm{C}$, ground in a commercial blender, and analyzed for chemical composition in the nutrition lab at Omaha's Henry Doorly Zoo and Aquarium (Iske et al. 2016). Fatty acid profiles of raw meat diets were determined by gas chromatography at Iowa State University (Richter et al. 2012). Peak identification and quantification (Kramer et al. 2008) were determined on esterified lipid samples (Christie 1972) extracted from each diet sample (Folch et al. 1957). Mineral analyses of raw meat diets were conducted at Midwest Laboratories (Omaha, NE) according to Method 985.01 (Horowitz \& Latimer 2006). Diet subsamples from each institution were sent to Arizona State University for analysis of vitamin A (retinol) and $\mathrm{E}$ ( $\alpha$-tocopherol) via reverse phase HPLC, as previously described (McGraw et al. 2006, Dierenfeld et al. 2009).

Weekly dietary intakes were calculated by multiplying the amount of diet fed by the number of days cats were fed per week, in order to account for variation in the number of fasting days. Weekly intakes were then multiplied by dry matter (DM) concentration of the diet to give weekly dry matter intake (DMI), which were then multiplied by nutrient content (\%) to yield weekly intakes of each nutrient on a dry matter basis (DMB). Whole prey items, defined as non-living, whole animal carcasses, included rabbit, rat, fish, guinea pig, chicken, and quail, were not analyzed for chemical composition because the frequency of feeding and size of whole prey items indicated these items accounted for less than $10 \%$ of each animal's diet.

\section{Population genetics}

Pedigree information for all snow leopards in US zoos dating back to 1903, including all of the males in this study, is maintained by the AZA in a regional studbook (Tupa 2019). This data set was analyzed with population management software (Ballou et al. 2011, Faust et al. 2012) to determine (1) the inbreeding coefficient (F) for each male based on the relatedness of their dam and sire and (2) the number of generations between each male and the population's founder animals from which they are descended (averaged for the maternal and paternal lineages). 


\section{Statistical analysis}

Multiple regression analysis was conducted using SAS ${ }^{\circledR}$ (SAS Inst. Inc. Cary, NC) with total sperm count and percent normal sperm morphology as the dependent variables and weekly dietary intake of macronutrients, fatty acids, vitamin A, and minerals, as well as seminal fluid measures of oxidative stress, as independent variables. Final statistical models only included significant variables. Age, body weight, frequency of feeding whole prey items, the number of fasting days, and genetic parameters for each animal were also analyzed via regression analyses.

Concentrations of fAM and fGM were log-transformed and analyzed using a linear mixed-effects model (including fixed and random effects) in R Core Team (2018) and R Studio Team (2018) using the REML method, assuming no within-group correlations in the nlme package (Pinheiro et al. 2018). Month was included as a fixed factor and male was included as a random factor. We measured the goodness of fit of the models by examining the correlation between model predictions and the observed data. We then examined the effects over time (across months) for the treatment identified as important from these models using Kruskall-Wallis ANOVA on Ranks with the Dunn's method for multiple comparisons using Sigma Stat (version 11.0; Systat Software, Inc., Chicago, IL).

The Mixed Model procedure of SAS was used to evaluate the fixed effects of diet type (single or multiple diet types fed), frequency that cats were fed whole prey items (less than once per week, once per week, more than once per week), age (3-6, 7-10, and 11-16 years), and body weight (30-33, 35-41, and 42-49 kg) on sperm quality using ANOVA. Least squared means were used for pairwise comparisons.

For all analyses, $P<0.05$ was considered indicative of a significant difference and $P<0.1$ was assumed to indicate a statistical trend. All means are presented \pm s.E.M.

\section{Results}

\section{Semen collections}

During a ten-year period between March 2009 and March 2019 , reproductive exams and semen collections $(n=41)$ were performed on 32 male snow leopards $(9.8 \pm 0.7$ years; $38.6 \pm 0.8 \mathrm{~kg}$ ) housed at 27 institutions (Table 1). The majority of males (23 of 32) were examined once, eight males were examined twice, and one male was examined three times, with 6 months to 4 years between collections. When multiple collections were performed on the same male, the mean values for all collections from that male were used for further analysis. Two males were unilaterally cryptorchid, but no other gross anatomical abnormalities were observed. Ejaculates $(2.9 \pm 0.2 \mathrm{~mL})$ contained $119.2 \pm 26.0 \times 10^{6}$ spermatozoa (range 0 to $663.0 \times 10^{6}$ ), of which $75.1 \pm 2.3 \%$ were motile and $28.6 \pm 2.6 \%$ exhibited normal morphology (Table 1). The most common abnormalities observed were spermatozoa with a proximal cytoplasmic droplet $(19.9 \pm 1.9 \%)$ and spermatozoa with a bent midpiece and a retained cytoplasmic droplet $(19.4 \pm 2.3 \%)$ (Table 1). Overall, $34.4 \%$ of evaluated males produced less than $5 \times 10^{6}$ sperm and $27.3 \%$ of males had ejaculates in which less than $20 \%$ of the spermatozoa exhibited normal morphology.

Age $\left(R^{2}=0.16, P<0.02\right)$ and testicular volume $\left(R^{2}=0.26, P<0.05\right)$ were weakly, but significantly, correlated with sperm number, with more sperm being recovered from younger males and/or males with greater testicular volume. When grouped by weight, cats weighing $35-41 \mathrm{~kg}$ tended $(P<0.10)$ to have a higher proportion of normal spermatozoa (33.6\%) than heavier cats (42$49 \mathrm{~kg}, 17.1 \%)$. Age and weight were not significantly correlated $\left(R^{2}=0.061, P>0.1\right)$. Neither testicular volume nor ejaculate volume $(P>0.2)$ were correlated with sperm morphology. The activity of SOD $\left(R^{2}=0.90\right)$ in seminal fluid samples ( $n=9$ males) was negatively correlated $(P<0.05)$ with sperm morphology. None of the other markers of oxidative stress were correlated with ejaculate traits.

\section{Husbandry}

Male snow leopards were cared for by two to seven people $($ mean $=5.3$ ) (Table 2). All males were exposed to seasonal fluctuations in photoperiod and housed in large exhibits (approximate area, range $600-5000 \mathrm{ft}^{2}$ ) with at least $12 \mathrm{ft}$ of vertical space (Table 2). All but one male was part of a regular behavioral training program (Table 2). Males received enrichment at least three times per week and 12 of 14 males were provided with enrichment on a daily basis (Table 2). Animal care staff classified their male's personality as calm in 12 of 14 cases and none of the males were considered aggressive by their caretakers (Table 2). None of the males were permanently housed in an enclosure adjacent to another large carnivore. https://raf.bioscientifica.com

https://doi.org/10.1530/RAF-20-0013 (c) 2020 The authors Published by Bioscientifica Ltd

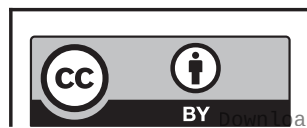

This work is licensed under a Creative Commons Attribution 4.0 International License. 
Table 1 Results of reproductive examinations and semen collections performed on male snow leopards ( $n=32$ males) between 2009 and 2019.

\begin{tabular}{l}
\hline \\
\hline Age at collection (years) \\
Body weight $(\mathrm{kg})$ \\
Total testicular volume $\left(\mathrm{cm}^{3}\right)$ \\
Ejaculate volume $(\mathrm{mL})$ \\
Ph \\
Total sperm count $\left(\mathrm{x} 10^{6}\right)$ \\
\%Motile \\
\%Morphologically normal \\
\%Morphologically abnormal \\
Proximal cytoplasmic droplet \\
Distal cytoplasmic droplet \\
Bent midpiece \\
Bent midpiece w/retained cytoplasmic droplet \\
Bent tail \\
Tightly coiled tail \\
Seminal fluid oxidative stress markers ${ }^{1}$ \\
Superoxide dismutase $(\mathrm{U} / \mathrm{mL})$ \\
DNA/RNA damage (ng/mL) \\
TBARS ( $\mu \mathrm{M})^{2}$ \\
Protein carbonyls ( $\mu \mathrm{M})$ \\
FRAP $(\mu M)^{3}$
\end{tabular}

\begin{tabular}{c}
\hline Mean $( \pm$ S.E.M. $)$ \\
\hline $9.8 \pm 0.7$ \\
$38.6 \pm 0.8$ \\
$18.5 \pm 0.8$ \\
$2.9 \pm 0.2$ \\
$8.6 \pm 0.05$ \\
$119.2 \pm 26.0$ \\
$75.1 \pm 2.3$ \\
$28.6 \pm 2.6$ \\
$19.9 \pm 1.9$ \\
$5.3 \pm 1.1$ \\
$8.7 \pm 1.0$ \\
$19.4 \pm 2.3$ \\
$9.0 \pm 1.2$ \\
$7.0 \pm 3.7$ \\
$3.3 \pm 0.8$ \\
$27.4 \pm 4.2$ \\
$8.7 \pm 0.8$ \\
$1.9 \pm 0.6$ \\
$165.3 \pm 19.7$
\end{tabular}

\begin{tabular}{c}
\hline Range \\
\hline $3-18$ \\
$30.5-48.9$ \\
$8.6-26.6$ \\
$0.8-5.5$ \\
$7.7-9.0$ \\
$0.0-663.0$ \\
$40.0-90.0$ \\
$6.0-48.5$ \\
$0.5-33.8$ \\
$0.0-21.0$ \\
$1.5-19.0$ \\
$1.5-45.5$ \\
$0.0-22.0$ \\
$0.0-81.5$ \\
$0.0-6.2$ \\
$9.3-47.4$ \\
$6.5-12.7$ \\
$0.0-5.5$ \\
$101.8-256.0$ \\
\hline
\end{tabular}

${ }^{1} n=9$ males examined during the 2016 breeding season using a 1:1 dilution of seminal fluid with culture medium; ${ }^{2}$ Thiobarbituric acid reactive substances; ${ }^{3}$ Ferric reducing antioxidant power.

\section{ACTH challenge}

Mean fGMs before the ACTH were $89.8 \pm 8.1 \mathrm{ng} / \mathrm{g}$ dry feces. FGMs (186.4 ng/g dry feces) increased on Day 2 after the ACTH injection (Fig. 1). This was a two-fold increase over mean fGM before injection. FGMs declined after Day 2 back to pre-injection values ( $90.9 \pm 35.8 \mathrm{ng} / \mathrm{g}$ dry feces).

\section{Endocrine analysis}

Concentrations of fAM ranged from $369.2 \pm 33.9$ to $992.5 \pm 114.5 \mathrm{ng} / \mathrm{g}$ dry feces and varied $\left(\mathrm{H}_{6}=39.72\right.$, $P<0.001)$ across months. Specifically, fAM peaked $(P<0.05)$ in February with the lowest concentrations in June (Fig. 2). Variation among males explained $28.3 \%$ of

Table 2 Questions asked of animal care staff regarding male snow leopard's $(n=14)$ environment and relevant husbandry practices.

\section{Survey Question}

How many keepers work with the male?

Approximate dimensions of the cat's holding and exhibit enclosures?

Is the cat exposed to seasonal changes in photoperiod and/or

temperature?

While on exhibit, does the male have the option of remaining hidden from the public?

Is the cat fed one or more commercial diet(s) with occasional whole prey items?

If given whole prey items, how often (days/month)?

How often does the male receive enrichment items?

Daily

$\geq 3 x$ per week

Is the male part of an active behavioral training program?

In your opinion, would you characterize the cat's temperament

Calm

Unpredictable

Nervous

\begin{tabular}{|c|c|c|}
\hline \multicolumn{3}{|c|}{ Results } \\
\hline Answers, $n$ & Mean \pm S.E.M. & Range \\
\hline Yes, 14 of 14 & $\begin{aligned} 5.3 & \pm 0.5 \\
249.6 & \pm 60.4 \mathrm{~m}^{2}\end{aligned}$ & $\begin{array}{c}2-7 \\
55.7-839.8\end{array}$ \\
\hline Yes, 14 of 14 & & \\
\hline Yes, 14 of 14 & & \\
\hline & $3.6 \pm 0.8$ & $1-12$ \\
\hline $\begin{array}{l}12 \text { of } 14 \\
2 \text { of } 14 \\
\text { Yes, } 13 \text { of } 14\end{array}$ & & \\
\hline $\begin{array}{l}12 \text { of } 14 \\
1 \text { of } 14 \\
1 \text { of } 14\end{array}$ & & \\
\hline
\end{tabular}

https://raf.bioscientifica.com

https://doi.org/10.1530/RAF-20-0013 (c) 2020 The authors Published by Bioscientifica Ltd

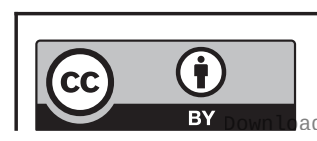

This work is licensed under a Creative Commons Attribution 4.0 International License. 
the variation in fAM concentrations not explained by month. Concentrations of fGM ranged from $55.1 \pm 1.9$ to $270.4 \pm 17.1 \mathrm{ng} / \mathrm{g}$ dry feces across the males, which accounted for $48.3 \%$ of the variation not explained by month. Concentrations were different $\left(\mathrm{H}_{6}=21.88\right.$, $P=0.001)$ across the months with January (114. $0 \pm 5.8$ ng/g dry feces) higher $(P<0.05)$ than April $(110.1 \pm 7.7$ ng/g dry feces) and May (104.6 $\pm 7.1 \mathrm{ng} / \mathrm{g}$ dry feces), but all other months were similar $(P<0.05)$ (mean, $111.1 \pm 4.3$; range, 97.0-114.2 ng/g dry feces). Neither fAM or fGM were correlated $\left(P \geq 0.2, R^{2} \leq 0.16\right)$ with the total number of spermatozoa collected or the proportion of spermatozoa with normal morphology (Figs 3 and 4).

\section{Nutrition}

All cats were fed raw, commercially manufactured beef, horse, or pork-based diets (900-1800 g as fed; 300-600 g DMB) from Nebraska Brand ${ }^{\circledR}$ (North Platte, NE), Triple A Brand Meat Company ${ }^{\odot}$ (Burlington, CO), Milliken Meat Products Ltd (Markham, Ontario), or Sustainable Swine Resources (Sheboygan Falls, WI) 4-7 days per week (0-3 fasting days/week). Whole prey items were provided $3.6 \pm 0.8$ days/month and accounted for less than $10 \%$ of the diet (by wet weight) due to the small size (e.g. rabbit, rat, fish, guinea pig, chicken, or quail) of these items. Cats that consumed a pork-based diet $(n=2)$ had more $(P<0.05)$ normal sperm $(45.8 \%)$ compared to those fed only horse $(26.6 \%)$ or beef $(11.3 \%)$. Cats fed whole prey once per week produced ejaculates with a higher $(P<0.05)$ proportion of normal spermatozoa $(37.2 \%)$ than cats fed whole prey less than once per week (14.6\%), but were not

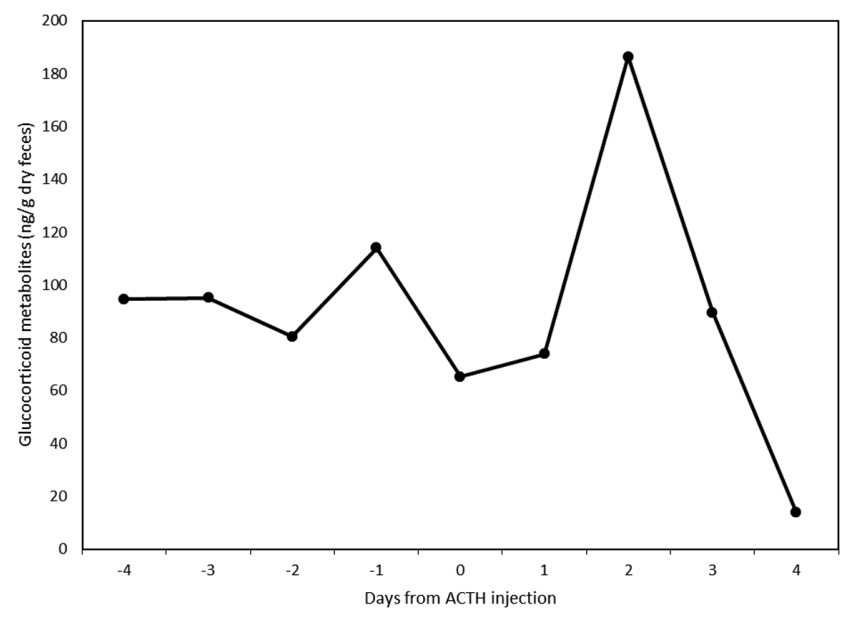

Figure 1 Fecal concentrations (ng/g dry feces) of glucocorticoid metabolites (fGM) in samples collected from one male snow leopard after an injection of adrenocorticotropin hormone (ACTH).

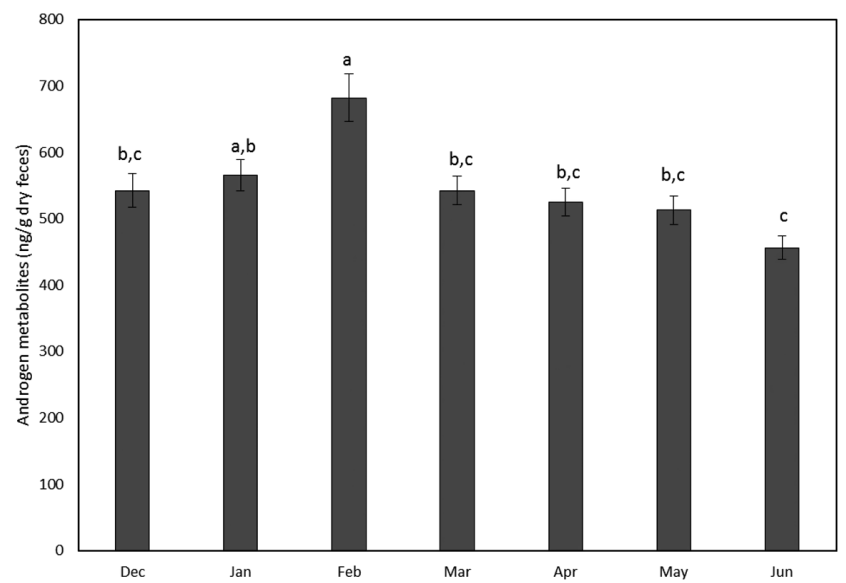

Figure 2 Fecal concentrations (ng/g; mean \pm S.E.M.) of androgen metabolites (fAM) in samples collected from 14 male snow leopards during each month of the breeding season. Different letters $(a, b, c)$ indicate a significant difference $(P<0.05)$ among months.

different than cats fed whole prey more than once per week $(27.5 \%)$. The number of times cats were fed whole prey items did not affect $(P>0.05)$ the total number of spermatozoa per ejaculate.

Weekly intakes of dry matter $(2274.8 \pm 186.2 \mathrm{~g})$, organic matter (2089.0 $\pm 170.3 \mathrm{~g})$, crude protein (1290.5 \pm 107.4
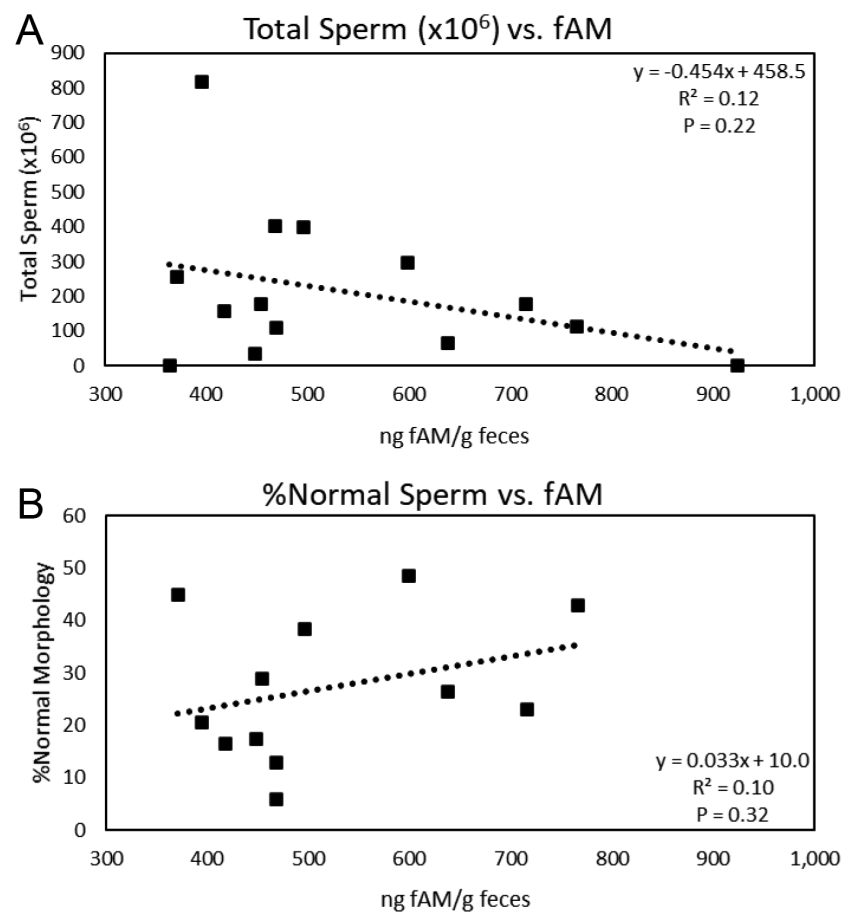

Figure $\mathbf{3}$ Linear regression analysis of the correlation between $(A)$ the total number of spermatozoa $\left(\times 10^{6}\right)$ per ejaculate and $(B)$ the proportion of spermatozoa with normal morphology and the mean concentration (ng/g) of fecal androgen metabolites (fAM) in samples collected throughout the same breeding season as the semen collection $(n=14$ males).

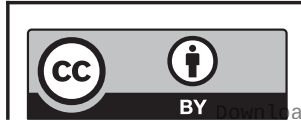

This work is licensed under a Creative Commons Attribution 4.0 International License. 

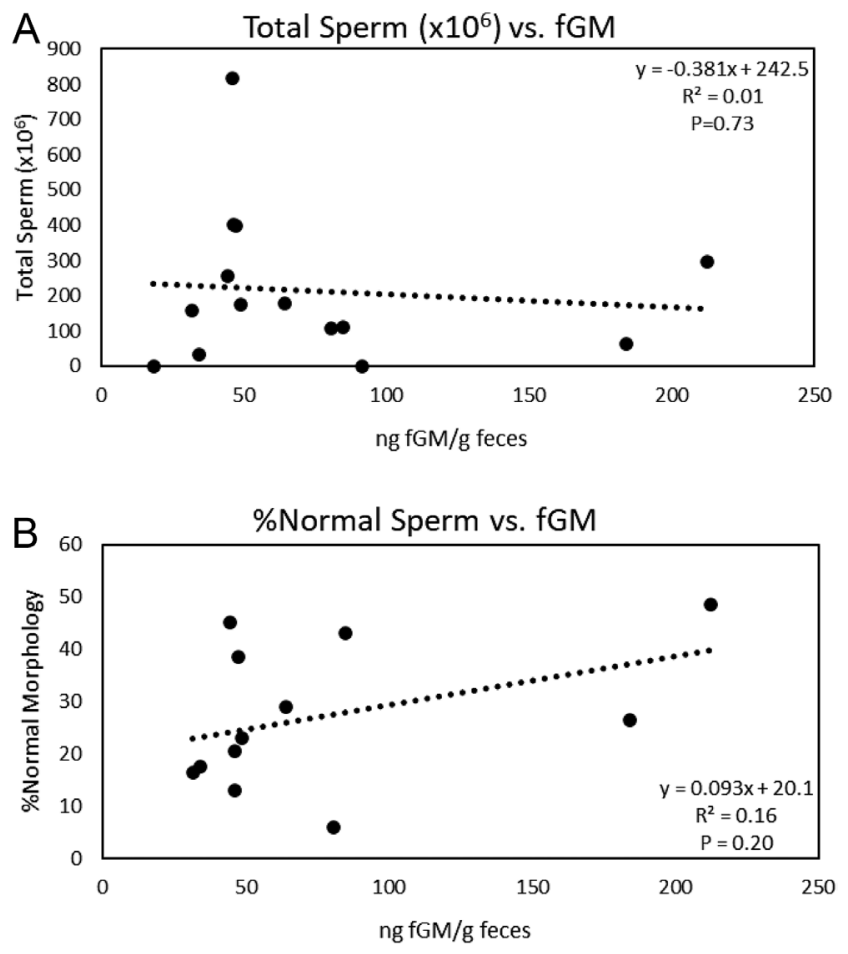

Figure 4 Linear regression analysis of the correlation between $(A)$ the total number of spermatozoa $\left(\times 10^{6}\right)$ per ejaculate and $(B)$ the proportion of spermatozoa with normal morphology and the mean baseline concentration (ng/g) of fecal glucocorticoid metabolites (fGM) in samples collected throughout the same breeding season as the semen collection ( $n=14$ males).

g), total fat (728.9 $\pm 74.0 \mathrm{~g})$, total dietary fiber $(122.3 \pm 11.6$ g) and metabolizable energy $(11,727.1 \pm 1014.4 \mathrm{kcal})$ were not correlated $(P>0.05)$ with reproductive traits (data not shown). Total sperm count was positively correlated $\left(P<0.05, R^{2}=0.86\right)$ with weekly intake of dietary polyunsaturated fatty acids (PUFA). Total sperm count also tended $(P<0.10)$ to be positively correlated with weekly intakes of dietary phosphorus $\left(R^{2}=0.27\right)$ and retinol (vitamin $\mathrm{A}, R^{2}=0.23$ ) and negatively correlated with weekly dietary intake of manganese $\left(R^{2}=0.21\right)$.
The proportion of spermatozoa with normal morphology was negatively correlated $(P<0.05)$ with weekly intake of retinyl acetate $\left(R^{2}=0.38\right)$ and magnesium $\left(R^{2}=0.29\right)$ and tended $(P<0.10)$ to be negatively correlated with weekly dietary intake of margaric acid $\left(R^{2}=0.31\right)$ and positively correlated with weekly copper intake $\left(R^{2}=0.31\right)$ (Table 3$)$.

A further investigation of the ingredient lists provided by the manufacturers indicated that two of the commercial diets (http://www.nebraskabrand.com/docs/ ClassicSheet2019pdf.pdf; http://www.nebraskabrand. com/docs/beefsheet2019pdf.pdf) contained soybean meal, which is known to contain bio-active phytoestrogens (Cederroth et al. 2010). Males fed these diets had reduced $(P<0.05)$ testicular volume $\left(17.9 \pm 1.6 \mathrm{~cm}^{3}\right)$ compared to males fed diets without added soy products $(23.8 \pm 1.4$ $\mathrm{cm}^{3}$ ), but the total number of sperm per ejaculate and the proportion of normal sperm were not different $(P>0.05)$. Diets with added soy products did not affect $(P>0.05)$ hormone concentrations (fAM and fGM), but there was a significant $(P<0.05)$ interaction between diet and month for both fAM and fGM (data not shown). Within each month, fAMs were not affected $(P>0.05)$ by diet. For males fed diets with added soy, fAM peaked $(P<0.05)$ in February, but were similar $(P>0.05)$ across other months. For males fed diets without added soy, fAMs were higher $(P<0.05)$ in February and January than in April and June. For fGMs, males on diets with added soy had higher $(P<0.05)$ fGM concentrations in February, March, April and June than males fed diets without added soy.

\section{Population genetics}

The 32 males in the study were $4.44 \pm 0.22$ generations descended from founders, including one wild-born individual (0 generations). The mean inbreeding coefficient was $0.018 \pm 0.003$, with all values (range, 0-0.052) falling below the estimated value for the

Table 3 Dietary variables (based on calculated weekly intake) that were correlated $(P<0.10)$ with the total number of spermatozoa per ejaculate or the proportion of spermatozoa with normal morphology in male snow leopards $(n=14)$.

\begin{tabular}{l}
\hline Ejaculate trait/weekly nutrient intake \\
\hline Total sperm $\left(\times 10^{6}\right)$ per ejaculate \\
Polyunsaturated fatty acids \\
Phosphorus \\
Manganese \\
Retinol \\
Proportion of spermatozoa with normal morphology \\
Retinyl acetate \\
Magnesium \\
Margaric acid \\
Copper
\end{tabular}

\begin{tabular}{c}
$\boldsymbol{R}^{\mathbf{2}}$ \\
\hline \\
0.86 \\
0.27 \\
0.21 \\
0.23 \\
\\
0.38 \\
0.29 \\
0.31 \\
0.31
\end{tabular}

\begin{tabular}{l}
$P$-value \\
\hline 0.0003 \\
0.06 \\
0.06 \\
0.08 \\
0.03 \\
0.04 \\
0.06 \\
0.07
\end{tabular}

Association

Positive Positive Negative Positive

Negative Negative Negative Positive (c) 2020 The authors Published by Bioscientifica Ltd

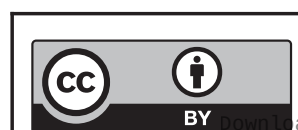

This work is licensed under a Creative Commons Attribution 4.0 International License. 
offspring of first cousins $(F=0.0625)$. Neither parameter was correlated $\left(R^{2}<0.1, P>0.2\right)$ with the total number of spermatozoa per ejaculate or the proportion of normal spermatozoa (data not shown).

\section{Discussion}

Snow leopards have been maintained in US zoos for over 100 years, with successful breeding programs starting in the 1950s and steady population growth until the early 1990s (Wharton \& Mainka 1997). Breeding success has declined in recent years and the sustainability of the zoobased population is uncertain. The current study was initiated to improve our understanding of reproduction in male snow leopards and identify factors that could be linked to recent declines in reproductive success. In a cohort of 32 male snow leopards, we found that $34 \%$ of males produced $<5$ million spermatozoa and $27 \%$ of males produced spermatozoa with $<20 \%$ normal morphology. Of the numerous endocrine, environmental, and genetic factors evaluated, weekly intake of polyunsaturated fatty acids was the only factor that was highly correlated with reproductive traits.

Ejaculate traits, including the quantity and quality of recovered spermatozoa, are known to vary widely between felid species (Howard 1993, Pukazhenthi et al. 2006b). For example, tigers (Panthera tigris) and ocelots (Leopardus pardalis) produce large quantities of spermatozoa with $>60 \%$ normal morphology, while the proportion of normal spermatozoa in the ejaculates of cheetahs (Acinonyx jubatus) and clouded leopards (Neofelis nebulosa) are $<20 \%$ (Byers et al. 1990, Howard 1993, Swanson et al. 2003, Pukazhenthi et al. 2006a, Crosier et al. 2007). Results from our current study would place snow leopards near the middle of this range, along with the majority of other felid species (Brown et al. 1991, Howard 1993, Swanson et al. 2003, Thiangtum et al. 2006, Herrick et al. 2010a). What is most alarming about our findings is not the number of spermatozoa or the proportion of spermatozoa with normal morphology, but how different our results are compared to previous studies of male snow leopards conducted in the early 1990s. In the previous studies, the total number of recovered spermatozoa ranged from 31 to $373 \times 10^{6}$ (Roth et al. 1996). The low end of this range $\left(31 \times 10^{6}\right)$ is significantly higher than values for $34 \%$ of the males in our study $\left(<5 \times 10^{6}\right.$ spermatozoa), including seven males with aspermic (no spermatozoa) ejaculates. Differences in the proportion of normal spermatozoa per ejaculate were even more dramatic, with $27 \%$ of the males in the current study exhibiting $<20 \%$ normal spermatozoa and none of the males in our study producing $>50 \%$ normal spermatozoa, compared to values as high as $63 \%$ normal spermatozoa in previous studies (Roth et al. 1994).

Studbook records indicate that 23 of the males in our study $(127.1 \pm 24.3$ million spermatozoa, $29.1 \pm 3.3 \%$ normal morphology) have sired at least one offspring in their lifetime. However, comparisons between these proven males and those males that have not sired offspring (unproven) are complicated due to the limited records available for each male's breeding history. Specifically, studbook records do not indicate if the male ever had access to a female, if that access occurred at times the female was receptive, if copulation actually occurred, and if the female was known to be fertile. For example, the male that produced the highest number of spermatozoa in this study has never sired offspring, but he has never been paired with a female. Even for the proven males, the ability to sire offspring earlier in their lives does not necessarily ensure fertility at the time of semen collection. As a result, we were not able to correlate ejaculate traits and fertility. However, studies of artificial insemination in domestic cats indicate that pregnancy can only be achieved using $<10$ million spermatozoa if those spermatozoa are deposited directly into the uterine horns or oviduct (Tsutsui et al. 2000, Swanson 2019). Similarly, extensive research comparing spermatozoa from normospermic $(>60 \%$ normal) and teratospermic ( $<40 \%$ normal) domestic cats have indicated that a low incidence of spermatozoa with normal morphology is associated with compromised sperm function, including capactitation, zona pellucida penetration, and oocyte activation (Howard et al. 1991, Long et al. 1996, Pukazhenthi et al. 1996, Villaverde et al . 2013).

Since the previous studies of snow leopards were performed on different animals by other researchers, procedural differences must be considered. All collections reported by Johnston et al. (1994) and some (proportion not specified) of the collections in Roth et al. (1996) utilized ketamine and xylazine to immobilize the males, compared to ketamine and medetomidine in the current study. Xylazine and medetomidine are both agonists of alpha-2 adrenergic receptors, but medetomidine has a higher binding affinity for these receptors than does xylazine (Schwartz \& Clark 1998) and is more effective than xylazine for inducing the release of spermatozoa into the urethra (Swanson et al. 2017), suggesting the use of medetomidine in the current study was not the cause of the reduced sperm recovery in the present study. The remaining collections reported by Roth et al. $(1994,1996)$

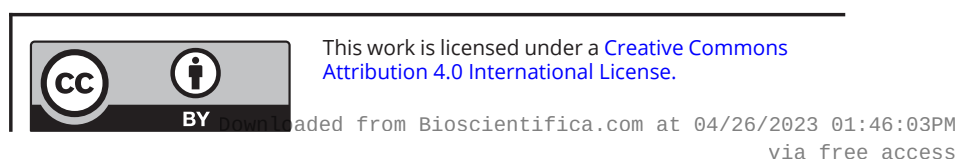


utilized a combination of tiletamine and zolazepam. In other species, this combination of drugs allows the recovery of ejaculates with similar volume, sperm concentration, motility, and morphology as collections using ketamine and medetomidine (Barros et al. 2009, Santiago-Moreno et al. 2011). In the previous and current studies, semen was collected by eletroejaculation using a similar size probe $(\sim 2.5 \mathrm{~cm})$, number of stimuli (80-90), and voltages (2-5 V) (Johnston et al. 1994, Roth et al. 1994, 1996). Finally, one of the co-authors of the Roth et al. studies (W.F. Swanson) trained J. Herrick on semen collection and evaluation in felids (Herrick et al. 2010a). For studies conducted by different personnel nearly $25 \mathrm{y}$ apart, methodologies were remarkably similar, and we feel confident that differences in ejaculate traits are representative of the populations at the time of collection and not an artifact of procedural changes over time.

If the quantity and quality of spermatozoa produced by male snow leopards has indeed declined in the last $20-25$ years, the obvious question is what factors have contributed to this change? Environmental factors can have a significant impact on reproductive success in felids (Mellen 1991, Wielebnowski et al. 2002a, Fazio et al. 2019). Although zoo exhibits and husbandry practices have improved in the last 20-25 years, with an ever-increasing emphasis on animal welfare, we do not always know how these changes affect reproduction. In the case of seasonally breeding species like snow leopards, exposure to an inappropriate photoperiod can alter gonadal activity (Brown et al. 2002, Graham et al. 2004, Newell-Fugate et al. 2007). Other factors, such as exhibit design, proximity to predators, and the relationship between animals and their caretakers have also been correlated to reproductive success (Mellen 1991, Koester et al. 2015, Fazio et al. 2019). Significant variation between husbandry practices at participating zoos made it difficult to statistically analyze the effects of some of these factors. However, available space and exposure to natural changes in photoperiod, two factors expected to be highly correlated with reproductive function in snow leopards, were remarkably similar across institutions. All institutions provided cats with enrichment multiple times per week, with most animals receiving some type of daily enrichment. The majority of the males also participated in positive reinforcement training programs, which has been associated with successful breeding in fishing cats (Prionailurus viverrinus) (Fazio et al. 2019). Although we did not objectively evaluate the relationship between males and their caregivers or animal temperament, the majority of keepers in our study felt that they had a good relationship with their animal and characterized the animal's temperament as calm.

Concentrations of fGM were also monitored throughout the breeding season (Graham \& Brown 1996) to provide some indication of the animal's perception of their environment and the amount of stress they are experiencing that may not have been apparent upon visual inspection of the enclosures by researchers (Carlstead et al. 1992, Carlstead et al. 1993, Wielebnowski et al. 2002a). The use of fGMs to evaluate snow leopard stress physiology was validated using an ACTH challenge, similar to observations in other felid species (Carlstead et al. 1992, Graham \& Brown 1996, Terio et al. 1999, Wielebnowski et al. 2002a, Young et al. 2004). There was no correlation between fGM and either the total number of recovered spermatozoa or the proportion of normal sperm per ejaculate, similar to reports in male cheetahs (Koester et al. 2015). However, ejaculate traits in the male cheetahs and ovarian activity in female cheetahs can be negatively influenced by public exposure and an increased number of care givers even though correlations with fGM were not significant. (Wielebnowski et al. 2002b, Koester et al. 2015, Koester et al. 2017). As pointed out by Koester et al. (2015), these results do not indicate ejaculate traits are independent of stress, just that the mechanism(s) affecting ejaculate traits in response to environmental/psychological stress may not be mediated by glucocorticoid secretion (MacDougallShackleton et al. 2019).

Monitoring concentrations of fAM is an effective means of determining the steroidogenic activity of the testes, allowing for the establishment of normative values for each species (Morais et al. 2002, Herrick et al. 2010a, Fanson et al. 2012), and characterization of seasonal patterns of reproduction in felids (Brown et al. 2002, Fanson et al. 2010). However, the relationship between androgen production, reflected in either serum or fecal concentrations, and ejaculate quality has not been well established. Single studies have reported correlations between serum androgen concentrations and the total number of spermatozoa recovered from cheetahs (Wildt et al. 1993) and the proportion of normal spermatozoa in domestic cats (Howard et al. 1990), but these same relationships have not been consistent in other studies (Brown et al. 1991, Barone et al. 1994, Muller et al. 2012, Koester et al. 2015). In the present study, the variation observed in the quantity of recovered spermatozoa or the proportion of normal spermatozoa per ejaculate in snow leopards was not correlated to androgen production.

Although diets for captive felids have been formulated to meet or exceed the National Research Council's 
(NRC) nutrient requirements for domestic cats, it is not always known how well these diets match the nutrient composition of the animal's natural diet or if and how specific nutrient requirements differ between domestic and exotic species. Similarly, dietary insufficiencies of vitamins, minerals, taurine, linoleic acid, and arachidonic acid negatively affect reproduction in domestic cats (MacDonald et al. 1984, Sturman 1991, Fascetti et al. 2000, Swanson et al. 2003), yet variations in these nutrients among diets for zoo carnivores are not well defined. Therefore, nondomestic species in zoos may experience subtle nutritional deficiencies or excesses that can affect their fertility, without overt effects on the animal's health (Allen \& Ullrey 2004, Howard \& Allen 2008). In the current study, dietary intake of various nutrients, including minerals (phosphorus and copper), fatty acids (PUFA), and retinol, were each positively correlated with sperm quantity or quality in male snow leopards, consistent with studies in other species (Huang \& Hembree 1979, Rode et al. 1995, Kowal et al. 2010, Safarinejad 2011, Risso et al. 2016, 2017, Narasimhaiah et al. 2018, Santos et al. 2019).

A retrospective analysis of the ingredients of the diets fed to the snow leopards in our study indicated that two of the diets fed to six males were supplemented with soy protein by the manufacturer. Soy products are a common source of dietary isoflavones with phytoestrogen activity that have been associated with reproductive dysfunction in males (Cederroth et al. 2010). For example, recent studies have suggested that the reduced fertility of southern white rhinoceroses (Ceratotherium simum simum) in zoos may be linked to the phytoestrogen content of their diets (Tubbs et al. 2016). The male snow leopards that were fed diets with added soy proteon had reduced testicular volume and altered patterns of androgen production during the breeding season, but no significant effects were seen on ejaculate traits or hormone concentrations. However, our analysis only took into consideration one potential source of phytoestrogen. The horses, cattle, and pigs, as well as rodents, rabbits, and birds, that made up the diets of the snow leopards were likely fed diets containing phytoestrogens prior to processing, which may have increased the content of phytoestrogens in the resulting meat (Gatta et al. 2013, Dal Bosco et al. 2015). Therefore, while the diets with the added soy protein likely contained more phytoestrogens than the other diets, none of the cats were fed a diet that can be assumed to be free of phytoestrogens and additional, controlled studies will be necessary to better understand these possible effects.
Male reproductive parameters can also be significantly affected by genetic diversity (Asa et al. 2007, Malo et al. 2010). In felids, male cheetahs, pumas, and lions from isolated populations with reduced genetic diversity have an increased incidence of spermatozoa with abnormal morphology (O'Brien et al. 1983, Brown et al. 1991, Roelke et al. 1993). In the absence of molecular data, we examined the correlation between pedigree derived inbreeding coefficients and ejaculate traits. However, inbreeding coefficients estimated from pedigree data are dependent on the assumption that the population's founders were unrelated. If founder animals were related, pairings in each generation could have higher levels of inbreeding than expected, and more genetic diversity could be lost over time than inbreeding coefficients suggest (Ito et al. 2017). In these cases, the loss of diversity over time may be reflected in correlations with the number of generations an individual is removed from the founders in their lineages. Although studies of molecular genetics in snow leopards are necessary to definitively exclude an effect of genetics, the lack of significant relationships between both inbreeding coefficient and generations from founders and the reproductive traits of males in our study suggests a limited role for genetics.

The results of this study provide a comprehensive assessment of ejaculate traits, endocrinology, husbandry, nutrition, and genetics in male snow leopards. It appears that a significant number of males in the current, US zoo population have reduced quantities of spermatozoa and an increased proportion of spermatozoa with abnormal morphology, which differs from previous reports of this same population in the 1990s. Although our sample size was relatively small (32 males, 14 males used for regression analysis with husbandry factors), it includes the equivalent of $46 \%$ of the males in the US population ( $n=69$ ), with regression analysis performed on $20 \%$ of these males. Of the factors evaluated, nutrition appeared to be the primary factor associated with reproductive traits, but prospective studies in which reproductive traits are evaluated following specific changes in diet composition are needed to validate our findings. Such controlled studies are especially important because some of the nutrients that were positively associated with ejaculate traits, have been associated with negative effects on reproduction and/or health when provided in excess (Gosselin et al. 1988, Bechert et al. 2002, Tvrda et al. 2015). Comparative studies in other species are also warranted, since all felid species maintained in US zoos are fed essentially the same diets. If controlled, https://raf.bioscientifica.com

https://doi.org/10.1530/RAF-20-0013 (c) 2020 The authors Published by Bioscientifica Ltd

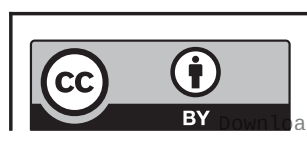

This work is licensed under a Creative Commons Attribution 4.0 International License. 
prospective studies verify a direct effect of nutrients on ejaculate traits, altering the composition of snow leopard diets could provide managers with a possible method of improving ejaculate traits in male snow leopards.

\section{Declaration of interest}

The authors declare that there is no conflict of interest that could be perceived as prejudicing the impartiality of the research reported.

\section{Funding}

This work was partially supported by AZA's Conservation Grants Funds (15-1304).

\section{Author contribution statement}

J R H designed the experiments and performed all reproductive exams, semen analyses, and husbandry practice surveys. C J I performed or coordinated all nutritional analyses, conducted assays for markers of oxidative stress, and completed relevant statistical tests. R M S validated assays for fecal androgen and glucocorticoid metabolites, supervised the analysis of samples by $\mathrm{M} \mathrm{A}$, and performed statistical analyses of all endocrine data. R L K provided laboratory supplies and salary for J R H. C L M assisted with nutritional analyses and data interpretation. $C \mathrm{~L}$ conducted studbook analysis and provided data on inbreeding coefficients and generations. All authors participated in manuscript preparation.

\section{Acknowledgements}

This research would not have been possible without the generous support and participation of veterinary and animal care staff at Albuquerque BioPark's Zoo, Akron Zoo, Binder Park Zoo, Blank Park Zoo, Chicago Zoological Society's Brookfield Zoo, Cheyenne Mountain Zoo, Como Park Zoo, Cincinnati Zoo and Botanical Garden, Dakota Zoo, Denver Zoo, Exotic Feline Breeding Center, Utah's Hogle Zoo, John Ball Zoo, Lincoln Children's Zoo, Miller Park, Northeastern Wisconsin Zoo and Adventure Park, Omaha's Henry Doorly Zoo and Aquarium, Oklahoma City Zoo, Philadelphia Zoo, Potawatomi Zoo, Potter Park Zoo, Rosamond Gifford Zoo, San Francisco Zoo, St. Louis Zoo, Turtle Back Zoo, Wildlife Conservation Society's Bronx Zoo, and Woodland Park Zoo. The authors are also grateful to Jay Tetzloff, Lynn Tupa, and the Snow Leopard SSP for their support of this work. Dr Bill Schoolcraft and Karen Maruniak at Colorado's Center for Reproductive Medicine are thanked for their support and assistance with this work.

\section{References}

Allen ME \& Ullrey DE 2004 Relationships among nutrition and reproduction and relevance for wild animals. Zoo Biology $\mathbf{2 3}$ 475-487. (https://doi.org/10.1002/zoo.20029)

Asa C, Miller P, Agnew M, Rebolledo JAR, Lindsey SL, Callahan M \& Bauman K 2007 Relationshop of inbreeding with sperm quality and reproductive success in Mexican grey wolves. Animal Conservation 10 326-331. (https://doi.org/10.1111/j.14691795.2007.00116.x)
Ballou JD, Lacy RC \& Pollak JP 2011 PMx: Software for Demographic and Genetic Analysis and Management of Pedigreed Populations, 1st ed. Brookfield, IL: Chicago Zoological Society.

Barone MA, Roelke ME, Howard JG, Brown JL, Anderson AE \& Wildt DE 1994 Reproductive characteristics of male Florida panthers: comparative studies from Florida, Texas, Colorado, Latin America, and North American Zoos. Journal of Mammalogy 75 150-162. (https://doi.org/10.2307/1382247)

Barros FF, Queiroz JP, Filho AC, Santos EA, Paula VV, Freitas CI \& Silva AR 2009 Use of two anesthetic combinations for semen collection by electroejaculation from captive coatis (Nasua nasua). Theriogenology 71 1261-1266. (https://doi.org/10.1016/j. theriogenology.2009.01.003)

Bechert U, Mortenson J, Dierenfeld ES, Cheeke P, Keller M, Holick M, Chen TC \& Rogers Q 2002 Diet composition and blood values of captive cheetahs (Acinonyx jubatus) fed either supplemented meat or commercial food preparations. Journal of Zoo and Wildlife Medicine 33 16-28. (https://doi.org/10.1638/10427260(2002)033[0016:DCABVO]2.0.CO;2)

Benzie IF \& Strain JJ 1996 The ferric reducing ability of plasma (FRAP) as a measure of "antioxidant power": the FRAP assay. Analytical Biochemistry 239 70-76. (https://doi.org/10.1006/abio.1996.0292)

Brown JL, Bush M, Packer C, Pusey AE, Monfort SL, O'Brien SJ, Janssen DL \& Wildt DE 1991 Developmental changes in pituitary-gonadal function in free-ranging lions (Panthera leo leo) of the Serengeti Plains and Ngorongoro Crater. Journal of Reproduction and Fertility 91 29-40. (https://doi.org/10.1530/jrf.0.0910029)

Brown JL, Wildt DE, Wielebnowski N, Goodrowe KL, Graham LH, Wells S \& Howard JG 1996 Reproductive activity in captive female cheetahs (Acinonyx jubatus) assessed by faecal steroids. Journal of Reproduction and Fertility 106 337-346. (https:// doi.org/10.1530/jrf.0.1060337)

Brown JL, Graham LH, Wu JM, Collins D \& Swanson WF 2002 Reproductive endocrine responses to photoperiod and exogenous gonadotropins in the Pallas' cat (Otocolobus manul). Zoo Biology 21 347-364. (https://doi.org/10.1002/zoo.10043)

Byers AP, Hunter AG, Seal US, Graham EF \& Tilson RL 1990 Effect of season on seminal traits and serum hormone concentrations in captive male Siberian tigers (Panthera tigris). Journal of Reproduction and Fertility 90 119-125. (https://doi. org/10.1530/jrf.0.0900119)

Carlstead K, Brown JL, Monfort SL, Killens R \& Wildt DE 1992 Urinary monitoring of adrenal reponses to psychological stressors in domestic and nondomestic felids. Zoo Biology 11 165-176. (https:// doi.org/10.1002/zoo.1430110305)

Carlstead K, Brown JL \& Seidensticker J 1993 Behavioral and adrenocortical responses to environmental changes in leopard cats (Felis bengalensis). Zoo Biology 12 321-331. (https://doi.org/10.1002/ zoo.1430120403)

Cederroth CR, Auger J, Zimmermann C, Eustache F \& Nef S 2010 Soy, phyto-oestrogens and male reproductive function: a review. International Journal of Andrology 33 304-316. (https://doi. org/10.1111/j.1365-2605.2009.01011.x)

Christie WW 1972 The preparation of alkyl esters from fatty acids and lipids. In Topics in Lipid Chemistry. Eds FD Gunstone. London: Logos Press.

Crosier AE, Pukazhenthi BS, Henghali JN, Howard J, Dickman AJ, Marker L \& Wildt DE 2006 Cryopreservation of spermatozoa from wild-born Namibian cheetahs (Acinonyx jubatus) and influence of glycerol on cryosurvival. Cryobiology 52 169-181. (https://doi.org/10.1016/j.cryobiol.2005.10.011)

Crosier AE, Marker L, Howard J, Pukazhenthi BS, Henghali JN \& Wildt DE 2007 Ejaculate traits in the Namibian cheetah (Acinonyx jubatus): influence of age, season and captivity. Reproduction, Fertility, and Development 19 370-382. (https://doi. org/10.1071/rd06057)

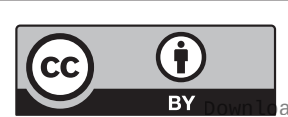


Dal Bosco A, Castellini C, Martino M, Mattioli S, Marconi O, Sileoni V, Ruggeri S, Tei F \& Benincasa P 2015 The effect of dietary alfalfa and flax sprouts on rabbit meat antioxidant content, lipid oxidation and fatty acid composition. Meat Science 106 31-37. (https://doi.org/10.1016/j.meatsci.2015.03.021)

Dierenfeld ES, Mcgraw KJ, fritsche K, Briggler JT \& Ettling J 2009 Nutrient composition of whole cryafish (Orconectes and Procambarus species) consumed by hellbender (Cryptobranchus alleganiensis). Herpetological Review 40 324-330.

Fanson KV, Wielebnowski NC, Shenk TM, Jakubas WJ, Squires JR \& Lucas JR 2010 Patterns of testicular activity in captive and wild Canada lynx (Lynx canadensis). General and Comparative Endocrinology 169 210-216. (https://doi.org/10.1016/j.ygcen.2010.09.001)

Fanson KV, Wielebnowski NC, Shenk TM \& Lucas JR 2012 Comparative patterns of adrenal activity in captive and wild Canada lynx (Lynx canadensis). Journal of Comparative Physiology: B, Biochemical, Systemic, and Environmental Physiology 182 157-165. (https://doi.org/10.1007/s00360-011-0597-8)

Fascetti AJ, Rogers QR \& Morris JG 2000 Dietary copper influences reproduction in cats. Journal of Nutrition 130 1287-1290. (https://doi. org/10.1093/jn/130.5.1287)

Faust LJ, Bergstrom YM, Thompson SD \& Bier L 2012 PopLink Version 2.4. Chicago, IL: Lincoln Park Zoo.

Fazio JM, Freeman EW, Bauer E, Rockwood L \& Parsons ECM 2019 Evaluation of management in North American zoos to enhance breeding success of the fishing cat (Prionailurus viverrinus) ex situ population. Zoo Biology 38 189-199. (https://doi.org/10.1002/ zoo.21465)

Folch J, Lees M \& Sloane Stanley GH 1957 A simple method for the isolation and purification of total lipides from animal tissues. Journal of Biological Chemistry 226 497-509.

Gatta D, Russo C, Giuliotti L, mannari C, Picciarelli P, Lombardi L, Giovannini L, Ceccarelli N \& Mariotti L 2013 Influence of partial replacement of soya bean meal by faba beans or peas in heavy pigs diet on meat quality, residual anti-nutritional factors and phytoestrogen content. Archives of Animal Nutrition 67 235-247. (https://doi.org/10.1080/1745039X.2013.801137)

Gosselin SJ, Loudy DL, Tarr MJ, Balistreri WF, Setchell KD, Johnston Jo, Kramer LW \& Dresser BL 1988 Veno-occlusive disease of the liver in captive cheetah. Veterinary Pathology 25 48-57. (https://doi.org/10.1177/030098588802500107)

Graham LH \& Brown JL 1996 Cortisol metabolism in the domestic cat and implications for non-invasive monitoring of adrenocortical function in endangered felids. Zoo Biology 15 71-82. (doi:10.1002/ (SICI)1098-2361(1996)15:1<71::AID-ZOO7>3.0.CO;2-9)

Graham LH, Swanson WF, Wildt DE \& Brown JL 2004 Influence of oral melatonin on natural and gonadotropin-induced ovarian function in the domestic cat. Theriogenology 61 1061-1076. (https:// doi.org/10.1016/j.theriogenology.2003.05.004)

Herrick JR 2019 In vitro culture of embryos from domestic cats. Methods in Molecular Biology 2006 229-246. (https://doi. org/10.1007/978-1-4939-9566-0_17)

Herrick JR, Bond JB, Campbell M, Levens G, Moore T, Benson K, D'Agostino J, West G, Okeson DM, Coke R et al. $2010 a$ Fecal endocrine profiles and ejaculate traits in black-footed cats (Felis nigripes) and sand cats (Felis margarita). General and Comparative Endocrinology 165 204-214. (https://doi.org/10.1016/j. ygcen.2009.06.021)

Herrick JR, campbell M, Levens G, Moore T, Benson K, D'Agostino J, West G, Okeson DM, Coke R, Portacio SC et al. $2010 b$ In vitro fertilization and sperm cryopreservation in the black-footed cat (Felis nigripes) and sand cat (Felis margarita). Biology of Reproduction $\mathbf{8 2}$ 552-562. (https://doi.org/10.1095/biolreprod.109.081034)

Horowitz W \& Latimer Jr GW 2006 Official Methods of Analysis of Association of Official Analytical Chemists International (AOAC). Gaithersburg, MD: AOAC International.
Howard JG 1993 Semen collection and analysis in carnivores. In Zoo and Wild Animal Medicine: Current Therapy 3, 3rd ed. Ed ME Fowler. Philadelphia, PA: W.B. Saunders.

Howard JG \& Allen ME 2008 Nutritional factors affecting semen quality in felids. In Zoo and Wild Animal Medicine, Current Therapy. Eds ME Fowler \& RE Miller. St. Louis, MO: Saunders Elsevier.

Howard JG, Brown JL, Bush M \& Wildt DE 1990 Teratospermic and normospermic domestic cats: ejaculate traits, pituitarygonadal hormones, and improvement of spermatozoal motility and morphology after swim-up processing. Journal of Andrology $\mathbf{1 1}$ 204-215.

Howard J, Bush M \& Wildt DE 1991 Teratospermia in domestic cats compromises penetration of zona-free hamster ova and cat zonae Pellucidae. Journal of Andrology 12 36-45.

Huang HF \& Hembree WC 1979 Spermatogenic response to vitamin A in vitamin A deficient rats. Biology of Reproduction 21 891-904. (https://doi.org/10.1095/biolreprod21.4.891)

Iske CJ, Morris CL \& Kappen KL 2016 Influence of pork and pork by-products on macronutrient and energy digestibility and palatability in large exotic felids. Journal of Animal Science 94 3738-3745. (https://doi.org/10.2527/jas.2016-0414)

Ito H, Ogden R, Langenhorst T \& Inoue-Murayama M 2017 Contrasting results from molecular and pedigree-based population diversity measures in captive zebra highlight challenges facing genetic management of zoo populations. Zoo Biology 36 87-94. (https://doi.org/10.1002/zoo.21342)

Jackson RM, Mishra C, Mccarthy TM \& Ale SB 2010 Snow leopards: conflict and conservation. In Biology and Conservation of Wild Felids. Eds DW Macdonald \& AJ Loveridge. New York, NY: Oxford University Press.

Johnston LA, Armstrong DL \& Brown JL 1994 Seasonal effects on seminal and endocrine traits in the captive snow leopard (Panthera uncia). Journal of Reproduction and Fertility 102 229-236. (https://doi. org/10.1530/jrf.0.1020229)

Koester DC, Freeman EW, Brown JL, Wildt DE, Terrell KA, Franklin AD \& Crosier AE 2015 Motile sperm output by male cheetahs (Acinonyx jubatus) managed ex situ is influenced by public exposure and number of care-givers. PLOS ONE 10 e0135847. (https://doi.org/10.1371/journal.pone.0135847)

Koester DC, Wildt DE, Brown JL, Meeks K \& Crosier AE 2017 Public exposure and number of conspecifics have no influence on ovarian and adrenal activity in the cheetah (Acinonyx jubatus). General and Comparative Endocrinology 243 120-129. (https://doi. org/10.1016/j.ygcen.2016.11.010)

Kowal M, Lenartowicz M, Pecio A, Golas A, Blaszkiewicz T \& Styrna J 2010 Copper metabolism disorders affect testes structure and gamete quality in male mice. Systems Biology in Reproductive Medicine 56 431-444. (https://doi. org/10.3109/19396361003734624)

Kramer JK, Hernandez M, Cruz-hernandez C, Kraft J \& Dugan ME 2008 Combining results of two GC separations partly achieves determination of all cis and trans 16:1, 18:1, 18:2 and 18:3 except CLA isomers of milk fat as demonstrated using Ag-ion SPE fractionation. Lipids 43 259-273. (https://doi.org/10.1007/s11745007-3143-4)

Loeding E, Thomas J, Bernier D \& Santymire R 2011 Using fecal hormonal and behavioral analyses to evaluate the introduction of two sable antelope at Lincoln Park Zoo. Journal of Applied Animal Welfare Science 14 220-246. (https://doi.org/10.1080/10888705.201 1.576968)

Long JA, Wildt DE, Wolfe BA, Critser JK, Derossi RV \& Howard J 1996 Sperm capacitation and the acrosome reaction are compromised in teratospermic domestic cats. Biology of Reproduction 54 638-646. (https://doi.org/10.1095/biolreprod54.3.638)

MacDonald ML, Rogers QR, Morris JG \& Cupps PT 1984 Effects of linoleate and arachidonate deficiencies on reproduction and

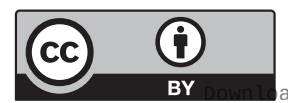

This work is licensed under a Creative Commons Attribution 4.0 International License. 
spermatogenesis in the cat. Journal of Nutrition 114 719-726. (https:// doi.org/10.1093/jn/114.4.719)

MacDougall-Shackleton SA, Bonier F, Romero LM \& Moore IT 2019 Glucocorticoids and 'stress' are not synonymous. Integrative Organismal Biology 1 1-8. (https://doi.org/10.1093/iob/obz017)

Malo AF, Martinez-Pastor F, Alaks G, Dubach J \& Lacy RC 2010 Effects of genetic captive-breeding protocols on sperm quality and fertility in the white-footed mouse. Biology of Reproduction $\mathbf{8 3}$ 540-548. (https://doi.org/10.1095/biolreprod.110.085316)

McCarthy T, Mallon D, Jackson R, Zahler P \& McCarthy K 2017 Panthera uncia: the IUCN Red List of Threatened Species 2017 [Online]. (available at: http://dx.doi.org/10.2305/IUCN.UK.2017-2. RLTS.T22732A50664030.en). Accessed on 29 September 2019.

McGraw KJ, Nolan PM \& Crino OL 2006 Carotenoid accumulation strategies for becoming a colourful House finch: analyses of plasma and liver pigments in wild moulting birds. Functional Ecology 20 678-688. (https://doi.org/10.1111/j.1365-2435.2006.01121.x)

Mellen JD 1991 Factors influencing reproductive success in small captive exotic felids (Felis spp.): a multiple regression analysis. Zoo Biology 10 95-110. (https://doi.org/10.1002/zoo.1430100202)

Morais RN, Mucciolo RG, Gomes ML, Lacerda O, Moraes W, Moreira N, Graham LH, Swanson WF \& Brown JL 2002 Seasonal analysis of semen characteristics, serum testosterone and fecal androgens in the ocelot (Leopardus pardalis), margay (L. wiedii) and tigrina (L. tigrinus). Theriogenology 57 2027-2041. (https://doi. org/10.1016/s0093-691x(02)00707-0)

Muller G, Martino-Andrade AJ, Santos AS, Reghelin AL, Garcia DM, Sant'ana GR, Spercoski KM, Meyer KB, Torres SM, Silva Junior VA et al. 2012 Testicular testosterone: estradiol ratio in domestic cats and its relationship to spermatogenesis and epididymal sperm morphology. Theriogenology 78 1224-1234. (https://doi.org/10.1016/j. theriogenology.2012.05.018)

Narasimhaiah M, Arunachalam A, Sellappan S, Mayasula VK, Guvvala PR, Ghosh SK, Chandra V, Ghosh J \& Kumar H 2018 Organic zinc and copper supplementation on antioxidant protective mechanism and their correlation with sperm functional characteristics in goats. Reproduction in Domestic Animals 53 644-654. (https://doi.org/10.1111/rda.13154)

Newell-Fugate A, Kennedy-Stoskopf S, Brown JL, Levine JF \& Swanson WF 2007 Seminal and endocrine characteristics of male Pallas' cats (Otocolobus manul) maintained under artificial lighting with simulated natural photoperiods. Zoo Biology 26 187-199. (https://doi.org/10.1002/zoo.20127)

O'Brien SJ, Wildt DE, Goldman D, Merril CR \& Bush M 1983 The cheetah is depauperate in genetic variation. Science 221 459-462. (https://doi.org/10.1126/science.221.4609.459)

Pinheiro J, Bates J, Debroy S, Sarkar D \& Team RC 2018 nlme: linear and nonlinear mixed effects models (Online). (available at: https://CRAN.R-project.org/package=nlme). Accessed.

Pukazhenthi BS, Wildt DE, Ottinger MA \& Howard J 1996 Compromised sperm protein phosphorylation after capacitation, swim-up, and zona pellucida exposure in teratospermic domestic cats. Journal of Andrology 17 409-419.

Pukazhenthi B, Laroe D, Crosier A, Bush LM, Spindler R, Pelican KM, Bush M, Howard JG \& Wildt DE $2006 a$ Challenges in cryopreservation of clouded leopard (Neofelis nebulosa) spermatozoa. Theriogenology 66 1790-1796. (https://doi. org/10.1016/j.theriogenology.2006.02.020)

Pukazhenthi BS, Neubauer K, Jewgenow K, Howard J \& Wildt DE 2006 $b$ The impact and potential etiology of teratospermia in the domestic cat and its wild relatives. Theriogenology 66 112-121. (https://doi.org/10.1016/j.theriogenology.2006.03.020)

R Core Team 2018 R: A Language and Environment for Statistical Computing, version 3.5.2. (Online). Vienna, Austria: R Foundation for Statistical Computing. (available at: https://www.R-project.org/)
R Studio Team 2018 R Studio: Integrated Development for $R$, version 1.1.463 (Online). Boston, MA: R Studio, Inc. (available at: http://www.rstudio. $\mathrm{com} /$ )

Reichert-Stewart JL, Santymire RM, Armstrong D, Harrison TM \& Herrick JR 2014 Fecal endocrine monitoring of reproduction in female snow leopards (Uncia uncia). Theriogenology 82 17-26. (https:// doi.org/10.1016/j.theriogenology.2014.02.018)

Richter EL, Drewnoski ME \& Hansen SL 2012 Effects of increased dietary sulfur on beef steer mineral status, performance, and meat fatty acid composition. Journal of Animal Science 90 3945-3953. (https://doi.org/10.2527/jas.2011-4512)

Risso A, Pellegrino FJ, Relling AE \& Corrada Y 2016 Effect of long-term fish oil supplementation on semen quality and serum testosterone concentrations in male dogs. International Journal of Fertility and Sterility 10 223-231. (https://doi.org/10.22074/ ijfs.2016.4913)

Risso AL, Pellegrino FJ, Corrada Y, Marmunti M, Gavazza M, Palacios A \& Relling AE 2017 Effect of fish oil and vitamin E on sperm lipid peroxidation in dogs. Journal of Nutritional Science $\mathbf{6}$ e48. (https://doi.org/10.1017/jns.2017.29)

Rode LM, Coulter GH, Kastelic JP \& Bailey DR 1995 Seminal quality and sperm production in beef bulls with chronic dietary vitamin A deficiency and subsequent re-alimentation. Theriogenology 43 1269-1277. (https://doi.org/10.1016/0093691x(95)00098-s)

Roelke ME, Martenson JS \& O'Brien SJ 1993 The consequences of demographic reduction and genetic depletion in the endangered Florida panther. Current Biology 3 340-350. (https://doi. org/10.1016/0960-9822(93)90197-v)

Roth TL, Howard JG, Donoghue AM, Swanson WF \& Wildt DE 1994 Function and culture requirements of snow leopard (Panthera uncia) spermatozoa in vitro. Journal of Reproduction and Fertility 101 563-569. (https://doi.org/10.1530/jrf.0.1010563)

Roth TL, Swanson WF, Collins D, Burton M, Garell DM \& Wildt DE 1996 Snow leopard (Panthera uncia) spermatozoa are sensitive to alkaline $\mathrm{pH}$, but motility in vitro is not influenced by protein or energy supplements. Journal of Andrology 17 558-566. (https://doi.org/10.1002/j.1939-4640.1996.tb01833.x)

Roth TL, Armstrong DL, Barrie MT \& Wildt DE 1997 Seasonal effects on ovarian responsiveness to exogenous gonadotrophins and successful artificial insemination in the snow leopard (Uncia uncia). Reproduction, Fertility, and Development 9 285-295. (https://doi. org/10.1071/r96048)

Safarinejad MR 2011 Effect of omega-3 polyunsaturated fatty acid supplementation on semen profile and enzymatic anti-oxidant capacity of seminal plasma in infertile men with idiopathic oligoasthenoteratospermia: a double-blind, placebo-controlled, randomised study. Andrologia 43 38-47. (https://doi.org/10.1111/ j.1439-0272.2009.01013.x)

Santiago-Moreno J, Toledano-Diaz A, Sookhthezary A, Gomez-Guillamon F, Salas De La Vega R, Pulido-Pastor A \& Lopez-Sebastian A 2011 effects of anesthetic protocols on electroejaculation variables of Iberian ibex (Capra pyrenaica). Research in Veterinary Science 90 150-155. (https://doi.org/10.1016/j. rvsc.2010.05.011)

Santos MC, Milani C, Zucchini P, Quirino CR, Romagnoli S \& Da Cunha ICN 2019 Residual effect after salmon oil supplementation on semen quality and serum levels of testosterone in dogs. Reproduction in Domestic Animals 54 1393-1399. (https://doi org/10.1111/rda.13530)

Santymire RM \& Armstrong DM 2010 Development of a fieldfriendly technique for fecal steroid extraction and storage using the African wild dog (Lycaon pictus). Zoo Biology 29 289-302. (https://doi. org/10.1002/zoo.20248)

Schell CJ, Young JK, Lonsdorf EV, Mateo JM \& Santymire RM 2017 Investigation of techniques to measure cortisol and

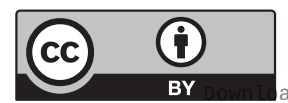

This work is licensed under a Creative Commons Attribution 4.0 International License. 
testosterone concentrations in coyote hair. Zoo Biology 36 220-225. (https://doi.org/10.1002/zoo.21359)

Schwartz DD \& Clark TP 1998 Affinity of detomidine, medetomidine and xylazine for alpha-2 adrenergic receptor subtypes. Journal of Veterinary Pharmacology and Therapeutics 21 107-111. (https://doi. org/10.1046/j.1365-2885.1998.00113.x)

Soulé M, Gilpin M, Conway W \& Foose T 1986 The Millenium Ark: how long a voyage, how many staterooms, how many passengers? Zoo Biology 5 101-113. (https://doi.org/10.1002/zoo.1430050205)

Sturman JA 1991 Dietary taurine and feline reproduction and development. Journal of Nutrition 121 (Supplement) S166-S170. (https://doi.org/10.1093/jn/121.suppl_11.S166)

Swanson WF 2019 Practical application of laparoscopic oviductal insemination for the propagation of domestic cats and wild felids. Reproduction, Fertility and Development 31 27-39.

Swanson WF, Johnson WE, Cambre RC, Citino SB, Quigley KB, Brousset DM, Morais RN, Moreira N, O'Brien SJ \& Wildt DE 2003 Reproductive status of endemic felid species in Latin American zoos and implications for ex situ conservation. Zoo Biology 22 421-441. (https://doi.org/10.1002/zoo.10093)

Swanson WF, Bateman HL \& Vansandt LM 2017 Urethral catheterization and sperm vitrification for simplified semen banking in felids. Reproduction in Domestic Animals 52 (Supplement 2) 255-260. (https://doi.org/10.1111/rda.12863)

Terio KA, Citino SB \& Brown JL 1999 Fecal cortisol metabolite analysis for noninvasive monitoring of adrenocortical function in the cheetah (Acinonyx jubatus). Journal of Zoo and Wildlife Medicine 30 484-491.

Tetzloff J, Tupa L \& Lynch C 2019 Population Analysis and Breeding Transfer Plan: Snow Leopard (Uncia uncia) AZA Species Survival Plan Yellow Program.

Thiangtum K, Swanson WF, Howard J, Tunwattana W, Tongthainan D, Wichasilpa W, Patumrattanathan $P$ \& Pinyopoommintr T 2006 Assessment of basic seminal characteristics, sperm cryopreservation and heterologous in vitro fertilisation in the fishing cat (Prionailurus viverrinus). Reproduction, Fertility, and Development 18 373-382. (https://doi.org/10.1071/ rd05098)

Tsutsui T, Tanaka A, Takagi Y, Nakagawa K, Fujimoto Y, Murai M, Anzai M \& Hori T 2000 Unilateral intrauterine horn insemination of fresh semen in cats. Journal of Veterinary Medical Science 62 1241-1245. (https://doi.org/10.1292/jvms.62.1241)

Tubbs CW, Moley LA, Ivy JA, Metrione LC, Laclaire S, Felton RG, Durrant BS \& Milnes MR 2016 Estrogenicity of captive southern white rhinoceros diets and their association with fertility. General and Comparative Endocrinology 238 32-38. (https://doi.org/10.1016/j. ygcen.2016.05.004)

Tupa L 2019 Snow Leopard (Uncia uncia) AZA Regional Studbook. Albuquerque: ABQ BioPark.

Tvrda E, Peer R, Sikka SC \& Agarwal A 2015 Iron and copper in male reproduction: a double-edged sword. Journal of Assisted Reproduction and Genetics 32 3-16. (https://doi.org/10.1007/s10815014-0344-7)

Villaverde AI, Fioratti EG, Fissore RA, He C, Lee HC, Souza FF, Landim-Alvarenga FC \& Lopes MD 2013 Identification of phospholipase $\mathrm{C}$ zeta in normospermic and teratospermic domestic cat sperm. Theriogenology 80 722-729. (https://doi.org/10.1016/j. theriogenology.2013.06.005)

Wharton D \& Mainka SA 1997 Management and husbandry of the snow leopard (Uncia uncia). International Zoo Yearbook 35 139-147. (https://doi.org/10.1111/j.1748-1090.1997.tb01203.x)

Wielebnowski NC, Fletchall N, Carlstead K, Busso JM \& Brown JL 2002a Noninvasive assessment of adrenal activity associated with husbandry and behavioral factors in the North American clouded leopard population. Zoo Biology 21 77-98. (https:// doi.org/10.1002/zoo.10005)

Wielebnowski NC, Ziegler K, Wildt DE, Lukas J \& Brown JL $2002 b$ Impact of social management on reproductive, adrenal and behavioural activity in the cheetah (Acinonyx jubatus). Animal Conservation 5 291-301. (https://doi.org/10.1017/S1367943002004043)

Wildt DE, Brown JL, Bush M, Barone MA, Cooper KA, Grisham J \& Howard JG 1993 Reproductive status of cheetahs (Acinonyx jubatus) in North American zoos: the benefits of physiological surveys for strategic planning. Zoo Biology 12 45-80. (https://doi. org/10.1002/zoo.1430120107)

Young KM, Walker SL, Lanthier C, Waddell WT, Monfort SI \& Brown JL 2004 Noninvasive monitoring of adrenocortical activity in carnivores by fecal glucocorticoid analyses. General and Comparative Endocrinology 137 148-165. (https://doi.org/10.1016/j. ygcen.2004.02.016)

Received in final form 12 October 2020

Accepted 15 October 2020

Accepted Manuscript published online 15 October 2020 https://raf.bioscientifica.com

https://doi.org/10.1530/RAF-20-0013 (c) 2020 The authors Published by Bioscientifica Ltd

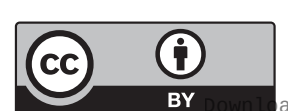

This work is licensed under a Creative Commons Attribution 4.0 International License. 